\title{
Role of the Pathotype-Specific ACRTS1 Gene Encoding a Hydroxylase Involved in the Biosynthesis of Host-Selective ACR-Toxin in the Rough Lemon Pathotype of Alternaria alternata
}

\author{
Yuriko Izumi, Eri Kamei, Yoko Miyamoto, Kouhei Ohtani, Akira Masunaka, Takeshi Fukumoto, \\ Kenji Gomi, Yasuomi Tada, Kazuya Ichimura, Tobin L. Peever, and Kazuya Akimitsu
}

First, second, third, fourth, fifth, sixth, seventh, eighth, ninth, and eleventh authors: Faculty of Agriculture, Kagawa University, Miki, Kagawa 761-0795 Japan; and tenth author: Department of Plant Pathology, Washington State University, Pullman, WA 99164-6430. Accepted for publication 16 April 2012.

\begin{abstract}
Izumi, Y., Kamei, E., Miyamoto, Y., Ohtani, K., Masunaka, A., Fukumoto, T., Gomi, K., Tada, Y., Ichimura, K., Peever, T. L., and Akimitsu, K. 2012. Role of pathotype-specific ACRTS1 gene encoding a hydroxylase involved in the biosynthesis of host-selective ACR-toxin in the rough lemon pathotype of Alternaria alternata. Phytopathology 102:741-748.

The rough lemon pathotype of Alternaria alternata produces hostselective ACR-toxin and causes Alternaria leaf spot disease of the rootstock species rough lemon (Citrus jambhiri) and Rangpur lime $(C$. limonia). Genes controlling toxin production were localized to a $1.5-\mathrm{Mb}$ chromosome carrying the ACR-toxin biosynthesis gene cluster (ACRT) in the genome of the rough lemon pathotype. A genomic BAC clone containing a portion of the $A C R T$ cluster was sequenced which allowed identification of three open reading frames present only in the genomes of

ACR-toxin producing isolates. We studied the functional role of one of these open reading frames, ACRTS1 encoding a putative hydroxylase, in ACR-toxin production by homologous recombination-mediated gene disruption. There are at least three copies of ACRTS1 gene in the genome and disruption of two copies of this gene significantly reduced ACR-toxin production as well as pathogenicity; however, transcription of ACRTS1 and production of ACR-toxin were not completely eliminated due to remaining functional copies of the gene. RNA-silencing was used to knock down the remaining ACRTS1 transcripts to levels undetectable by reverse transcription-polymerase chain reaction. The silenced transformants did not produce detectable ACR-toxin and were not pathogenic. These results indicate that ACRTS1 is an essential gene in ACR-toxin biosynthesis in the rough lemon pathotype of A. alternata and is required for full virulence of this fungus.
\end{abstract}

Seven strains of Alternaria alternata (Fr.) Keissler are known to produce host-selective toxins (HSTs) and each is selectively toxic to a particular plant cultivar $(24,39)$. HSTs of A. alternata are low-molecular-weight, secondary metabolites that induce disease symptoms and have the same specificity as infection by the toxin-producing pathogen $(39,46,50-52)$. Despite their close phylogenetic relationship $(27,42)$, each pathotype can be distinguished by specificity on their respective host plants. Only a susceptible host can develop symptoms after inoculation with the pathotype or after treatment with the HST produced by the pathotype. The chemical structures of HSTs from six pathotypes of $A$. alternata have been elucidated (24). HST-biosynthetic genes were recently cloned from the Japanese pear pathotype, strawberry pathotype, tangerine pathotype, tomato pathotype, and apple pathotypes, and a series of studies for disruption and silencing of these genes identified that production of the HST by each pathotype is required for pathogenicity $(1,3,4,14-20,29$, 30,32-34,44,47,48).

The rough lemon pathotype of A. alternata causes Alternaria leaf spot disease of the common citrus root stock species rough lemon (Citrus jambhiri Lush.) and Rangpur lime (C. limonia Osbeck). The latter is a hybrid of rough lemon and acid mandarin

Corresponding author: K. Akimitsu; E-mail address: kazuya@ag.kagawa-u.ac.jp

* The $e$-Xtra logo stands for "electronic extra" and indicates that the online version contains three supplemental figures. Figures 4 and 5 appear in color online.

The first two authors contributed equally to this research.

http://dx.doi.org/10.1094/PHYTO-02-12-0021-R

(C) 2012 The American Phytopathological Society
$(7,26,22)$. The pathogen produces host-specific ACR-toxin $(12,26$, 39). The structure of the major form of ACR-toxin (ACR-toxin-I, $\mathrm{MW}=496$ ) consists of a dihydropyrone ring with a polyalcohol side chain (Supplemental Figure 1) (12,37). The molecular mechanisms conferring sensitivity to ACR in rough lemon have been identified $(6,11,40)$. The target site of ACR-toxin is the mitochondrion, and the toxin causes mitochondrial dysfunction in rough lemon $(6,23)$. ACR-toxin uncouples oxidative phosphorylation and also causes leakage of cofactor $\mathrm{NAD}^{+}$from the TCA cycle (6). The gene ACRS (ACR-toxin Sensitivity gene) that confers sensitivity in Citrus species to ACR-toxin was identified from the mitochondrial genome of rough lemon (40). This gene confers ACR-toxin sensitivity to Escherichia coli, and addition of the toxin at a minimum concentration of $50 \mathrm{nM}$ completely abolished oxygen uptake by $A C R S$-expressing $E$. coli. Sequence analysis demonstrated that $A C R S$ is located within the intron of the mitochondrial tRNA-Ala gene, and encodes an amphihilic helix type of tetrameric transmembrane receptor-like protein (40). ACRS transcript analysis demonstrated that toxin sensitivity was not controlled by presence or absence of ACRS but rather by posttranscriptional modification of the ACRS transcript (40).

A. alternata HST biosynthetic genes are clustered on small chromosomes generally less than $2 \mathrm{Mb}(1,2,5,14,16,18,19,29,32-$ 34). Masunaka et al. (29) found that strains of the rough lemon pathotype similarly carried a small chromosome of 1.2 to $1.5 \mathrm{Mb}$, and the presence of this chromosome was correlated with production of ACR-toxin and pathogenicity to rough lemon. Most genes controlling HST production in A. alternata have multiple paralogs $(1,2,5,14,16,18,19,29,32-34)$, making it difficult to disrupt all functional copies of the gene using homologous recombination- 
mediated gene disruption. To overcome this problem, RNA silencing has been used to knock down transcripts from all functional copies. An example of this approach was the use of RNA silencing of the tangerine pathotype HST biosynthesis gene ACTT2, which encodes a putative hydrolase and is present in multiple copies in the genome of this pathotype (33).

The combined use of homologous recombination-mediated gene disruption and RNA silencing allowed us to functionally analyze an HST biosynthesis gene with multiple paralogs in the rough lemon pathotype. In this study, we identify and characterize the first ACR-toxin synthesis gene, ACRTS1 from the small 1.5$\mathrm{Mb}$ chromosome in the rough lemon pathotype of A. alternata. The occurrence of ACRTS1 encoding a putative hydroxylase among several pathogenic and nonpathogenic strains was highly correlated to ACR-toxin production and pathogenicity. Disruption of two copies of this gene significantly reduced ACR-toxin production as well as pathogenicity, and toxin production and pathogenicity were not detectable following further inactivation of ACRTS1 by RNA silencing.

\section{MATERIALS AND METHODS}

Plants and fungal strains. Young leaves (midrib length 2 to $4 \mathrm{~cm}$ ) from rough lemon grown in the greenhouse were used for toxin sensitivity and pathogenicity assays as described previously $(1,6,29,30,32-34,40)$. Rough lemon is susceptible to the rough lemon pathotype of A. alternata and sensitive to ACR-toxin $(22,26)$. Isolates $\mathrm{HC} 1,7,8$, and $\mathrm{BC} 19,27$, and 35 (41) were used as reference rough lemon pathotype isolates (29). Isolate BC3-51-OS2A, a dual pathotype isolate that produces both ACT-toxin and ACR-toxin (29), was also used as a reference ACR-toxin producing isolate. Isolates $\mathrm{SH} 11,12,13,14,15,18,19,20,21$, and EV10, 13, 14, and 24 (41) were used as reference tangerine pathotype isolates $(29,30,32-34,41,42)$. Isolates HC14, BC17, $\mathrm{BC} 36$, and O-94 were used as reference nonpathogenic, citrusassociated isolates $(29,30,32-34,41,42)$ and the Alternaria black rot pathogen A. citri (ATCC58171) was also used as a nontoxicgenic and nonpathogenic isolate (17). Non-citrus-associated $A$. alternata included Japanese pear pathotype isolates G31 and G90-A2, strawberry pathotype isolates NAF-3 and NAF-8, tomato pathotype isolates 91080804 and AL-4, apple pathotype isolates AM-1 and O-159, and tobacco pathotype isolates No. 122-2 and AT-204 $(18,32)$ provided by T. Tsuge, Nagoya University, Japan, and H. Otani, Tottori University. All isolates were stored in $25 \%$ ( vol/vol) glycerol at $-80^{\circ} \mathrm{C}$, and cultures for each experiment were initiated from the stocks by growth on V8 juice agar or potato dextrose agar (PDA) plates.

Nucleic acid manipulations. Genomic DNA and total RNA extractions, genomic polymerase chain reaction (PCR) and reverse transcription PCR (RT-PCR), and Southern blot hybridizations using DIG-PCR-labeled probes (Roche, Basel, Switzerland) were carried out as previously described (1,17,29,30,32-34). Restriction enzyme digestion of genomic DNA ( $5 \mu \mathrm{g})$, agarose gel electrophoresis, and capillary transfer were conducted under standard conditions. A BAC library was constructed from $A$. alternata rough lemon pathotype isolate HC1 (41). Approximately $100 \mathrm{~kb}$ of Sau3AI-digested genomic DNA fragments from $\mathrm{HC} 1$ separated by pulse field gel electrophoresis (PFGE) was ligated into the BamHI site of a pcc1 BACTM vector (Epicentre, Madison, WI) and transformed into E. coli (DH10B) (Invitrogen, San Diego, CA) by electroporation as described previously (34). The genomic BAC library was screened by colony hybridization with a DIG-labeled RP10-2 probe generated from the $1.5-\mathrm{Mb}$ chromosome of the rough lemon pathotype isolate HC1 (29). BAC DNA was extracted as described previously (34), and the insert of BAC clone $3 \mathrm{M} 8$ was sequenced to $5 \times$ redundancy by shotgun sequencing following the manufacturer's protocol (Shimadze, Tsukuba, Japan). Putative open reading frames (ORFs) were identified using BESTORF (http://linux1.softberry. com/berry.phtml) from the sequence of the respective contigs by mass sequencing.

Transcripts of ACRTS1 were amplified with or without addition of reverse transcriptase (Invitrogen) by RT-PCR using either primer pair ACRTS1F1 (5'-CAGATTGGTACCTCACT-3') and ACRTS1R2 (5'-GAGCGGCTGTGACGAAGTTGATATC- $\left.3^{\prime}\right)$ for cloning and detection of ACRTS1 (Table 1). Primer pair actinFor (5'-AGATGACACAGATTGTTTTCGAGACC-3') and actinRev (5'-AGTTGAAAGTGGTGACGTGGATACC-3') (Table 1) for the actin gene act 1 of $A$. alternata (AY748985) was used as a control. RT-PCR using the Thermoscript RT-PCR system (Invitrogen) was performed with $30 \mathrm{PCR}$ cycles (denaturing for $30 \mathrm{~s}$ at $94^{\circ} \mathrm{C}$, primer annealing for $30 \mathrm{~s}$ at $56^{\circ} \mathrm{C}$, and extension for $1.5 \mathrm{~min}$ at $\left.72^{\circ} \mathrm{C}\right)$ with total RNA ( $\left.1 \mu \mathrm{g}\right)$ as the template. RT-PCR products were either subcloned into pGEM-T Easy (Promega, Madison, WI) or transferred to Hybond- $\mathrm{N}^{+}$membranes (Amersham Biosciences, Piscataway, NJ) after separation in agarose gels using standard methods and detected with DIG-labeled PCR amplicons of ACRTS1 probe using primer pair ACRTS1F1 and

TABLE 1. Sequences of gene-specific primers used in this study

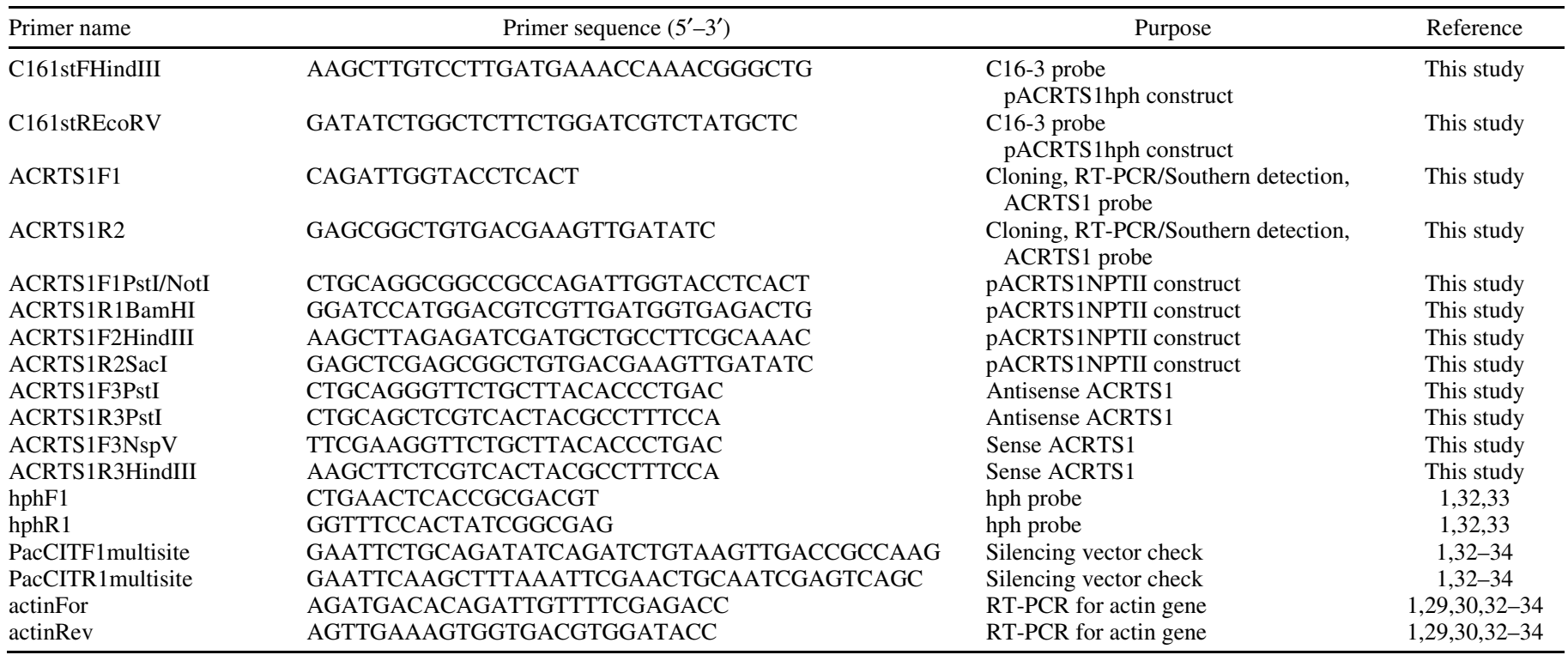


ACRTS1R2 with the method described previously $(1,17,29,30$, 32-34). Sequencing was performed by the dideoxy chain termination method (45) using an ABI PRISM Dye Termination Cycle Sequencing Ready Reaction Kit (Applied Biosystems, Foster City, CA) and an automated fluorescent DNA sequencer (Model 310, Applied Biosystems). Sequence identities were estimated using BLAST and FASTA searches of the DNA Data Bank of Japan (http://www.ddbj.nig.ac.jp/), and domain and motif analyses were performed using Pfam (http://www.pfam. sanger.ac.uk/).

Plasmid vector constructs and fungal transformation. The gene targeting vector pACRTS1hph was constructed using partial ACRTS1 sequence amplified by PCR consisting of 30 cycles (denaturing for $30 \mathrm{~s}$ at $94^{\circ} \mathrm{C}$, primer annealing for $30 \mathrm{~s}$ at $55^{\circ} \mathrm{C}$, and extension for $1.5 \mathrm{~min}$ at $72^{\circ} \mathrm{C}$ ) with the primer set C161stFHindIII (5'-AAGCTTGTCCTTGATGAAACCAAACG GGCTG-3') and C161stREcoRV (5'-GATATCTGGCTCTTC TGGATCGTCTATGCTC-3') (Table 1), which contained HindIII and EcoRV digestion sites in the sequence. The partial ACRTS1 sequence amplified by PCR was first subcloned into the HindIII and EcoRV sites of subcloning vector pAHY, constructed with pT7Blue-2 (Novagen, Madison, WI) and carrying the $\operatorname{trpC}$ promoter, $h p h$ and $\operatorname{trpC}$ terminator cassettes at BamHI and EcoRV sites as described previously $(32,34)$. Both the pAHY and the partial ACRTS1 sequence were digested with HindIII and EcoRV and then ligated to produce pACRTS1hph. The gene replacement vector pACRTS1NPTII was constructed using two partial sequences of ACRTS1 amplified by PCR under the same conditions as described above with respective primer sets ACRTS1F1PstI/NotI (5'-CTGCAGGCGGCCGCCAGATTGG TACCTCACT- $\left.3^{\prime}\right)$ and ACRTS1R1BamHI (5'-GGATCCATG GACGTCGTTGATGGTGAGACTG-3'), or ACRTS1F2HindIII (5'-AAGCTTAGAGATCGATGCTGCCTTCGCAAAC-3') and ACRTS1R2SacI (5'-GAGCTCGAGCGGCTGTGACGAAGTTG ATATC-3'), respectively (Table 1). One of the ACRTS1PCR fragments amplified with primer set ACRTS1F1PstI/NotI and ACRTS1R1BamHI was digested with PstI and BamHI and subcloned into the same sites of the pGEM-T::NPTII, which was constructed with pGEM-T Easy (Promega) carrying a trpC promoter, NPTII and trpC terminator cassette at BamHI and HindIII (34). Another ACRTS1 PCR fragment amplified with primer set ACRTS1F2HindIII and ACRTS1R2SacI was digested with HindIII and SacI, and then subcloned into the same sites of the vector containing the first partial ACRTS1 fragment to produce pACRTS1NPTII.

Plasmid vector pASY containing the intron region of $\mathrm{AcPacC}$ (accession AB433595) as the head of the dsRNA hairpin structure was prepared as previously described $(32,34)$ and used as the RNA silencing vector for ACRS1 transcripts in the rough lemon pathotype. For construction of the pASY-ACRTS1 RNA-silencing vector, sense and antisense inserts of ACRTS1 were amplified by PCR consisting of 30 cycles (denaturing for $30 \mathrm{~s}$ at $94^{\circ} \mathrm{C}$, primer annealing for $30 \mathrm{~s}$ at $66^{\circ} \mathrm{C}$, and extension for $1.5 \mathrm{~min}$ at $72^{\circ} \mathrm{C}$ ) using either primer set ACRTS1F3PstI (5'-CTGCAGGG TTCTGCTTACACCCTGAC-3') containing a Pst I site and ACRTS1R3PstI (5'-CTGCAGCTCGTCACTACGCCTTTCCA3') containing a PstI site, or ACRTS1F3NspV (5'-TTCGAA GGTTCTGCTTACACCCTGAC-3') containing a $N s p \mathrm{~V}$ site and ACRTS1R3HindIII (5'-AAGCTTCTCGTCACTACGCCTTTC CA-3') containing a HindIII, respectively (Table 1). The PCR product for antisense ACRTS1 amplified with ACRTS1F3PstI and ACRTS1R3PstI was digested with PstI and then ligated between the $\operatorname{trp} C$ promoter and the spacer region of the RNA silencing vector pASY $(32,34)$ digested with Pst I following dephosphorylation with alkaline phosphatase (Takara, Shiga, Japan). The PCR product of sense ACRTS1 amplified with ACRTS1F3NspV and ACRTS1R3HindIII was ligated at the region between the spacer region and $\operatorname{trpC}$ terminator of the pASY containing antisense ACRTS1 digested with $N s p \mathrm{~V}$ and HindIII. The constructed vector of pASY-ACRTS1 for RNA silencing of ACRTS1 was confirmed by PCR and sequencing using primer set PacCITF1multisite (5'-GAATTCTGCAGATATCAGATCTGTA AGTTGACCGCCAAG-3') designed from the spacer region in the internal vector construct and ACRTS1R3HindIII for sense insertion, or primer set PacCITR1multisite (5'-GAAT TCAAGCTTTAAATTCGAACTGCAATCGAGTCAGC-3') and ACRTS1R3PstI for antisense insertion (Table 1).

Protoplasts were prepared and isolate $\mathrm{HC1}$ or its mutants transformed using standard methods. Protoplasts $\left(1 \times 10^{7}\right)$ were transformed with $3 \mu \mathrm{g}$ of each vector using methods described previously $(1,17,29,30,32-34)$. Colonies were transferred to PDA plates containing hygromycin B $(50 \mu \mathrm{g} / \mathrm{ml})$ or geneticin $(200 \mu \mathrm{g} / \mathrm{ml})$ and grown at $24^{\circ} \mathrm{C}$ for 5 to 7 days, and single spore cultures were recovered as described previously $(1,17,29,30$, 32-34).

Detection of plasmid integration, ACR-toxin production and pathogenicity. Integration patterns of transformation vectors for targeted gene disruption and gene replacement were determined using genomic Southern blots hybridized to the ACRTS1 probe with AatI-digested genomic DNA from each of the respective transformants. Hybridization and detection conditions for Southern blots were as described previously $(1,17,29,30$, 32-34). Integration of the RNA-silencing vector was determined by genomic PCR using the primer set of either PacCITF1multisite and ACRTS1R3HindIII (amplification of sense), PacCITR1multisite and ACRTS1R3PstI (amplification of antisense) or hphF1 (5'-CTGAACTCACCGCGACGT-3') and hphR1 (5'-GGTTTCCACTATCGGCGAG-3') with genomic DNA as the template (Table 1). PCR products using both primer sets PacCITF1multisite/ACRTS1R3HindIII and PacCITR1multisite/ ACRTS1R3PstI were sequenced for confirmation. The PCR products using primer set hphF1/hphR1 were further analyzed by Southern blot with DIG-labeled $h p h$ probe prepared using the same primer set.

ACR-toxin produced by 128 independent ACRTS1-silenced transformants was initially quantified by bioassay by placing dilute culture filtrates $\left(10^{1}\right.$ to $10^{3}$ in water) onto wounded sites of young leaves of rough lemon as previously described $(6,22,26,29,40)$. Leaves were incubated in a moist chamber at $24^{\circ} \mathrm{C}$ in the dark and observed for necrosis development after 48 h. Transformants causing less than $50 \%$ necrosis compared to the wild type isolate $\mathrm{HCl}$ were scored as mutants with reduced ability to cause necrosis. The mutants which gave no necrosis development by this assay were further examined by thin-layer chromatography (TLC) analysis for ACR-toxin production and an inoculation assay to determine pathogenicity. For TLC analysis of ACR-toxin production in culture filtrates, A. alternata strain $\mathrm{HC} 1$ and its mutants were grown in 200-ml flasks containing $50 \mathrm{ml}$ of AC-toxin medium $(6,22,26,29,40)$ for 20 to 25 days at $24^{\circ} \mathrm{C}$. The presence of ACR-toxin in the extracts was identified by a TLC system employing silica gel 60 F254 TLC plates (Merck, Darmstadt, Germany). Ethyl acetate extracts were obtained using a benzene/acetone/acetic acid solvent system (60:40:1, vol/vol), and ACR-toxin was detected as a purple spot on plates under UV illumination at $254 \mathrm{~nm}$. An authentic preparation of ACR-toxin was prepared from culture filtrates of isolate $\mathrm{HC} 1$ as previously described $(6,22,26,29,40)$.

For pathogenicity tests, conidia of each isolate were collected from mycelial mats grown in potato dextrose broth for 3 weeks. Conidia were suspended in water at $1 \times 10^{5}$ conidia $/ \mathrm{ml}$ and used to inoculate on the lower surface of detached young leaves (midrib length 3.0 to $4.0 \mathrm{~cm}$ ) of ACR-toxin-sensitive citrus cultivar rough lemon as described previously (1,29,30,32-34). Leaves were incubated in a moist chamber at $24^{\circ} \mathrm{C}$ in the dark, and the development of leaf spots and necrosis was monitored for $48 \mathrm{~h}$. 


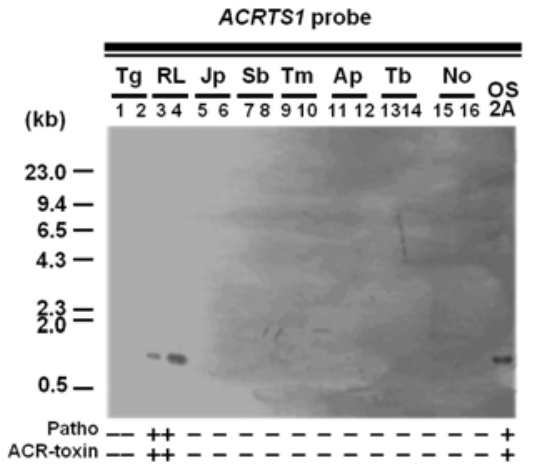

B

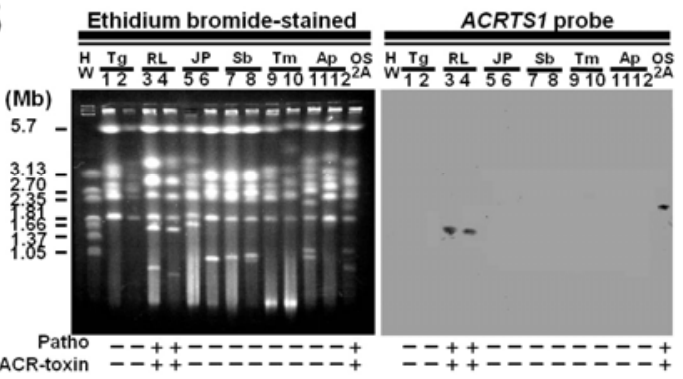

C
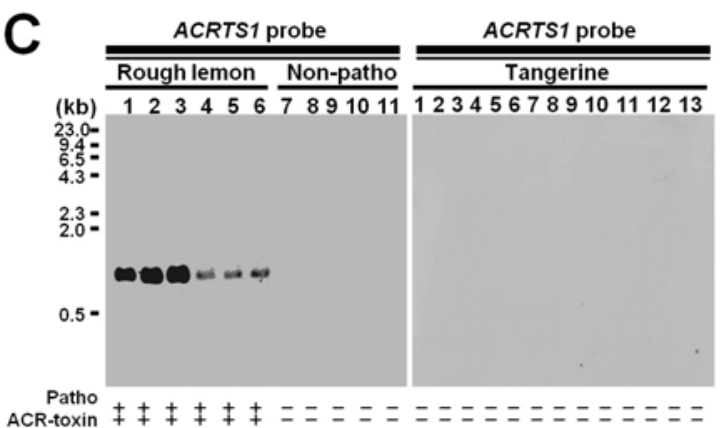

Fig. 1. Distribution of ACRTS1 among different Alternaria alternata pathotypes and saprophytic strains. A, Southern blot analysis for distribution of ACRTS1 among seven pathotypes, two nonpathogenic isolates, and a dual pathotype of A. alternata. Genomic DNA of each fungus was digested with EcoRV. Abbreviations used in $\mathbf{A}$ are Tg: tangerine pathotype isolates SH11 and SH20 (lanes 1 and 2), RL: rough lemon pathotype isolates HC1 and HC8 (lanes 3 and 4), JP: Japanese pear pathotype isolates G31 and G90-A2 (lanes 5 and 6), Sb: strawberry pathotype isolates NAF-3 and NAF-8 (lanes 7 and 8), Tm: tomato pathotype isolates 91080804 and AL-4 (lanes 9 and 10), Ap: apple pathotype, isolates AM-1 and O-159 (lanes 11 and 12), Tb: tobacco pathotype, isolates no. 122-2 and AT204 (lanes 13 and 14), No: nonpathogenic isolates O-94 and $\mathrm{HC} 14$ (lanes 15 and 16), OS2A: dual pathotype, isolate BC3-5-1-OS2A (lane 17). Sizes of DNA marker fragments (HindIII-digested $\lambda$ DNA) are indicated at left. B, Chromosomal location of ACRTS1 among various A. alternata pathotypes. Intact chromosomes of each isolate were separated with PFGE in an $0.8 \%$ agarose gel (left panel). Chromosomes were transferred to a nylon membrane and hybridized with DIG-labeled ACRTS1 probe (right panel). Chromosome size markers in $\mathrm{Mb}$ for Saccharomyces cerevisiae are indicated at left. Abbreviations and isolates used in respective lanes are Tg: tangerine pathotype isolates SH11 and SH20 (lanes 1 and 2), $\mathrm{RL}$ : rough lemon pathotype isolates $\mathrm{HC1}$ and $\mathrm{HC} 8$ (lanes 3 and 4), JP: Japanese pear pathotype isolates G31 and G90-A2 (lanes 5 and 6), Sb: strawberry pathotype isolates NAF-3 and NAF-8 (lanes 7 and 8), Tm: tomato pathotype isolates 91080804 and AL-4 (lanes 9 and 10), Ap: apple pathotype, isolates AM-1 and O-159 (lanes 11 and 12), OS2A: dual pathotype, isolate BC3-5-1-OS2A (lane 13). C, Southern blot analysis of the distribution of ACRTS1 among rough lemon pathotype (Rough lemon) and nonpathogenic (Non-patho) strains (left panel), and tangerine pathotype strains (right panel). Genomic DNA of each strain was digested with EcoRV. Sizes of DNA marker fragments (HindIII-digested $\lambda \mathrm{DNA}$ ) are indicated at left. Isolates in each lane of the left panel from lanes 1 to 11 are $\mathrm{HC} 1, \mathrm{HC} 7, \mathrm{HC} 8, \mathrm{BC} 19, \mathrm{BC} 27, \mathrm{BC} 35$, $\mathrm{HC} 14, \mathrm{BC} 17, \mathrm{O}-94, \mathrm{BC} 36$, and A. citri. Isolates in each lane of the right panel from lanes 1 to 13 are SH11, SH12, SH13, SH14, SH15, SH18, SH19, SH20, SH21, EV10, EV13, EV14, and EV24. Pathogenicity of each strain on rough lemon young leaves and ACR-toxin production are indicated as (+) or (-) at the bottom of both panels.
PFGE and hybridization. Preparation of fungal protoplasts for separation of chromosomes by PFGE and running conditions for PFGE were as described previously (1,29,30,32-34). Running conditions (duration, voltage, linear gradient of switching time) in the PFGE apparatus (CHEF-DRII, Bio-Rad, Richmond, CA) consisted of $0.5 \times$ Tris-borate-EDTA (TBE) at $8^{\circ} \mathrm{C}$ in $0.8 \%$ (wt/vol) agarose gel (Seakem Gold agarose; Cambrex BioScience Rockland, Rockland, ME), 25 h/1.6 V/cm/500 s, 30 h/1.6 $\mathrm{V} / \mathrm{cm} / 1,000 \mathrm{~s}, 50 \mathrm{~h} / 1.6 \mathrm{~V} / \mathrm{cm} / 1,500 \mathrm{~s}$, and $32 \mathrm{~h} / 1.6 \mathrm{~V} / \mathrm{cm} / 2,000 \mathrm{~s}$. Chromosomal DNA bands were visualized by ethidium bromide staining. For transfer to membranes, the gel was soaked in $0.2 \mathrm{~N}$ $\mathrm{HCl}$ for 20 min (to nick chromosomal DNA), 0.4 N NaOH plus $1.5 \mathrm{M} \mathrm{NaCl}$ for $1 \mathrm{~h}$ to transfer to Hybond- $\mathrm{N}^{+}$membranes (Amersham Biosciences) by alkaline capillary transfer with $0.4 \mathrm{~N}$ $\mathrm{NaOH}$ and $1.5 \mathrm{M} \mathrm{NaCl}$ for $48 \mathrm{~h}$. The membrane was baked at $80^{\circ} \mathrm{C}$ for $2 \mathrm{~h}$ to fix the DNA and hybridized at $68^{\circ} \mathrm{C}$ overnight with ACRTS1 probes. Hybridization and washes were conducted under high stringency conditions according to the manufacturer's instructions as described previously $(1,29,30,32-34)$.

\section{RESULTS}

Cloning of ACRTS1 from the rough lemon pathotype of $A$. alternata and distribution among $A$. alternata pathotypes. A genomic BAC library from rough lemon isolate HC1 was screened by colony hybridization with the RP10-2 probe generated from the $1.5-\mathrm{Mb}$ chromosome of the rough lemon pathotype isolate $\mathrm{HC} 1$ (29). BAC clone 3M8 hybridized to the probe and shotgun sequencing of the insert (approximately $100 \mathrm{~kb}$ ) identified 16 contigs with sizes from 756 to 58,600 bp (total contig length $114,285 \mathrm{bp}$ ) with an average redundancy of 5.34 from a total of $610,740 \mathrm{bp}$ of sequence data. Thirty-two putative ORFs were identified from these contigs, and probes for genomic Southern blots were prepared from the internal regions of the respective putative ORFs. The distribution of the putative ORFs among genomic DNA of several isolates of the seven pathotypes of A. alternata that produce different HSTs was examined, and three putative ORFs were identified to be present only in the genome from the rough lemon pathotype of A. alternata (data not shown). One of the three ORFs was amplified and subcloned from BAC clone 3M8 using a set of primers (ACRTS1F1 and ACRTS1R2) designed at the $5^{\prime}$ and $3^{\prime}$ noncoding regions of the ORF, and the sequence of cDNA was obtained by RT-PCR with the same primer set to obtain the entire transcript. The ORF encoded a putative hydroxylase based on FASTA, BLAST, Pfam searches and was designated as ACRTS1 (accession no. AB688098). This 1,391 bp ORF was predicted to contain four introns and encode a protein of 375 amino acids (Supplemental Figure 2).

The distribution of ACRTS1 in the genomes of seven $A$. alternata pathotypes that produce different HSTs, nonpathogenic strains of A. alternata, or the dual pathotype strain BC3-5-1OS2A was examined by genomic PFGE and Southern blotting (Fig. 1A and B). The distribution of ACRTS1 in the genomes of several different isolates of the rough lemon pathotype (6 isolates), tangerine pathotype (13 isolates), and nonpathogenic $A$. alternata (5 isolates) was also examined (Fig. 1C). The ACRTS1 probe only hybridized to the genome of ACR-toxin producers (rough lemon pathotype and dual-pathotype isolates) (Fig. 1A to C), indicating that the presence of ACRTS1 was correlated to ACR-toxin production. PFGE and Southern blots demonstrated that ACRTS1 is located on a single small chromosome of $1.5 \mathrm{Mb}$ in the rough lemon pathotype ( $\mathrm{HCl}$ and $\mathrm{HC} 8)$ and $2.0 \mathrm{Mb}$ in BC3-5-1-OS2A (Fig. 1B). The distribution of ACRTS1 in the genome of isolate $\mathrm{HC} 1$ of the rough lemon pathotype was further examined (Fig. 2). The ACRTS1 probe detected one fragment when genomic DNA was digested with BamHI, EcoRI, XbaI, EcoRV, SalI, XhoI, or KpnI, which have no predicted restriction 
site within the probe sequence, and two bands were observed upon digestion with $S a c I$, which has one predicted restriction site within the ACRTS1 probe sequence (Fig. 2). However, multiple bands were observed upon digestion with HindIII and PstI, which have no predicted restriction site within the sequence of the ACRTS1 probe (Fig. 2), indicating the presence of multiple ACRTS1 copies with different restriction sites in the flanking DNA or within the ORF region in the genome of isolate $\mathrm{HC1}$ (Fig. 2).

Targeted gene disruption of ACRTS1 for functional analysis of ACR-toxin biosynthesis. To examine the role of ACRTS1 in ACR-toxin production and pathogenicity, we constructed a targeting vector pACRTS1hph containing a partial region of ACRTS1 in pT7-blue2 (Novagen) for disruption of ACRTS1 by homologous recombination (Fig. 3A). This vector was transformed into the isolate $\mathrm{HCl}$ of the rough lemon pathotype. We screened for reduction in ACR-toxin production using the leaf necrosis assay and for insertion of the vector construct using Southern hybridization. Transformant D16 was identified which produced less toxin in culture filtrates than wild type and had a shift of a 7-kb ACRTS1 band present in the wild type to a 14-kb band in the transformant (Fig. 3C) which was the predicted shift of bands based on the map of ACRTS1 region (Fig. 3A) and indicated insertion of the vector construct at the target site. The remaining 7-kb band indicated the presence of multiple copies of ACRTS1 (Fig. 3C). Transcript analysis of ACRTS1 by RT-PCR with primer set ACRTS1F1 and ACRTS1R1 generated an amplicon of the predicted size from total RNA of wild type and transformant D16, and the products hybridized to the ACRTS1 probe (Fig. 4A). The intensity of the band was reduced but not eliminated in transformant D16 compared to that of the wild type (Fig. 4A). The PCR reaction without addition of reverse transcriptase did not amplify any product (Fig. 4A). The actin gene, which is expressed constitutively in this fungus, was amplified to similar levels as observed for the wild type (Fig. 4A). TLC analysis detected a spot for ACR-toxin from the extract from single disruptant D16 with an authentic ACR-toxin Rf value of 0.24 (Fig. 4B). When the lower leaf surfaces of susceptible

\section{ACRTS1 probe}

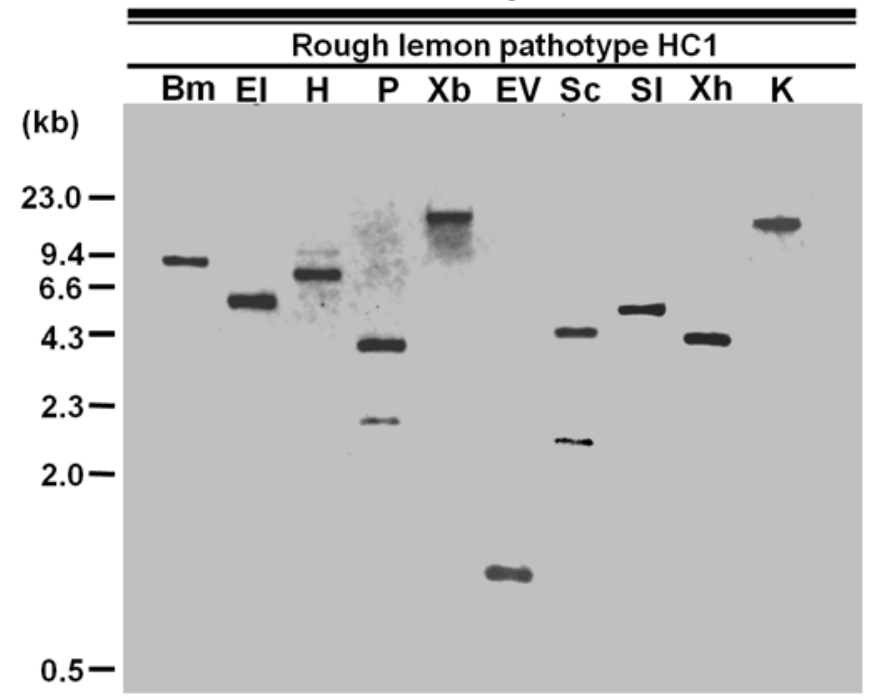

Fig. 2. Southern blot analysis of ACRTS1 hybridized to genomic DNA from Alternaria alternata rough lemon pathotype digested with different restriction enzymes. Genomic DNA of wild-type isolate $\mathrm{HC} 1$ was digested with BamHI (lane Bm), EcoRI (EI), HindIII (H), Pst I (P), XbaI (Xb), EcoRV (EV), SacI (S), SalI (Sl), XhoI (Xh), or KpnI (K). Digested DNA was transferred to nylon membrane and probed with a DIG-labeled ACRTS1 probe. Sizes of DNA marker fragments (HindIII-digested $\lambda \mathrm{DNA}$ ) are indicated to the left in kilobases. cultivar rough lemon were inoculated with spores of transformant D16, typical leaf spots appeared, but disease severity was dramatically reduced relative to that caused by the wild-type strain (Fig. 4C).

Gene replacement vector pACRTS1NPTII containing two partial regions of ACRTS1 in pT7-blue2 (Novagen) was also constructed for disruption of remaining copy of ACRTS1 in D16 transformant by gene replacement (Fig. 3B). When we screened for reduction in ACR-toxin production by leaf necrosis assay and for insertion of the vector construct by Southern hybridization, we identified transformant Rep28, which had further reduction of toxin production in culture filtrates and a shift of the 7-kb ACRTS1 band present in the wild type to $10-\mathrm{kb}$ addition to the $14-$ $\mathrm{kb}$ bands observed in the transformant D16 (Fig. 3C). These were the predicted shifts of bands based on the map of ACRTS1 region (Fig. 3B), indicating another insertion of the vector construct at the target site in other copy of ACRTS1. However, the presence of the 7-kb band indicated the presence of remaining copies of ACRTS1 (Fig. 3C). Transcript analysis of ACRTS1 by RT-PCR with primer set ACRTS1F1 and ACRTS1R1 from total RNA of wild type and transformant Rep28 indicated that intensity of the band was significantly reduced but not eliminated completely in transformant Rep28 (Fig. 4A). TLC analysis also detected a faint but detectable spot of ACR-toxin from the extract from the double disruptant Rep28 with an Rf value of 0.24 (Fig. 4B). Inoculation of rough lemon leaves with Rep28 resulted in necrotic spots although the number of spots was limited (Fig. 4C).

Use of RNA silencing for functional disruption of ACRTS1. The efficiency of RNA silencing had been established previously using the green fluorescent protein $(G F P)$ gene and the $A C T T 2$ or ACTTS2 genes in the tangerine pathotype of A. alternata (1,33). A plasmid vector pASY-ACRTS1 which created a double-stranded hairpin ACRTS1 RNAs with sense and antisense sequences of ACRTS1 in pASY was constructed, and $3 \mu \mathrm{g}$ of the vector pASYACRTS1 was transformed with pSH75 carrying $h p h$ as a selection marker $(32,34)$ into the wild-type $\mathrm{HC} 1$.

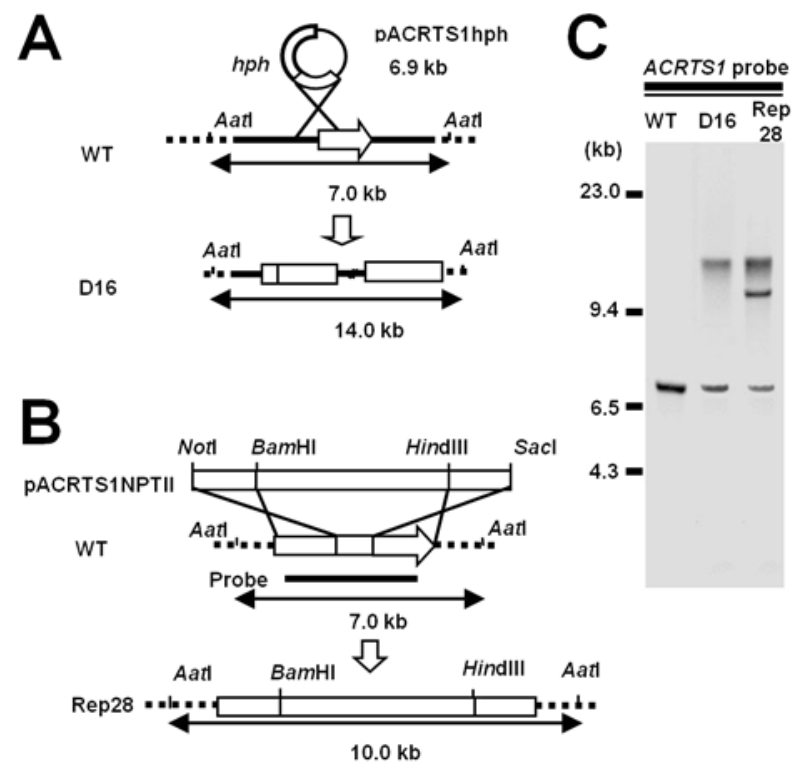

Fig. 3. Targeted gene disruption of ACRTS1 in Alternaria alternata rough lemon pathotype. A, Disruption construct pACRTS1hph and integration pattern of the vector in the single-copy disruptant D16. B, Disruption construct pACRTS1NPTII and predicted integration pattern of the vector in the double-copy disruptant Rep28. C, Genomic Southern blot of ACRTS1 in wild type (HC1), single-copy disruptant D16, and double-copy disruptant Rep28. Genomic DNA was digested with Aat I and fractionated by agarose gel followed by hybridization with ACRTS1 probe. Sizes of DNA marker fragments (HindIII-digested $\lambda$ DNA) are indicated to the left. 
When 128 transformants were assessed for resistance to hygromycin B using a plate growth assay and for production of ACR-toxin in culture filtrates using a leaf necrosis assay, 125 transformants had reduced ability to induce necrosis compared to the wild-type HC1. These transformants were further examined by TLC for loss of ACR-toxin production and by pathogenicity test, and three transformants (S14, 3H6, and 3H8) were selected. Insertion of pASY-ACRTS1 in these transformants was confirmed by PCR amplifications of the vector-specific region and $h p h$ region as shown in Figure 5A. The ACRTS1 transcript was undetectable by RT-PCR (Fig. 5B), and no spot for ACR-toxin was detected with TLC (Fig. 5C). Leaves inoculated with conidia of the wild type were covered with necrotic spot lesions, but no lesions developed on leaves inoculated with conidia of S14 (Fig. 5D). Transformants of $3 \mathrm{H} 6$ and $3 \mathrm{H} 8$ also had phenotypes identical to that of $\mathrm{S} 14$ (data not shown). No significant differences in culture growth rate (Fig. 5E), sporulation or spore germination were found between the wild type and the singlecopy disruptant D16, two-copy disruptant Rep28, or the ACRTS1 RNA-silenced transformants.
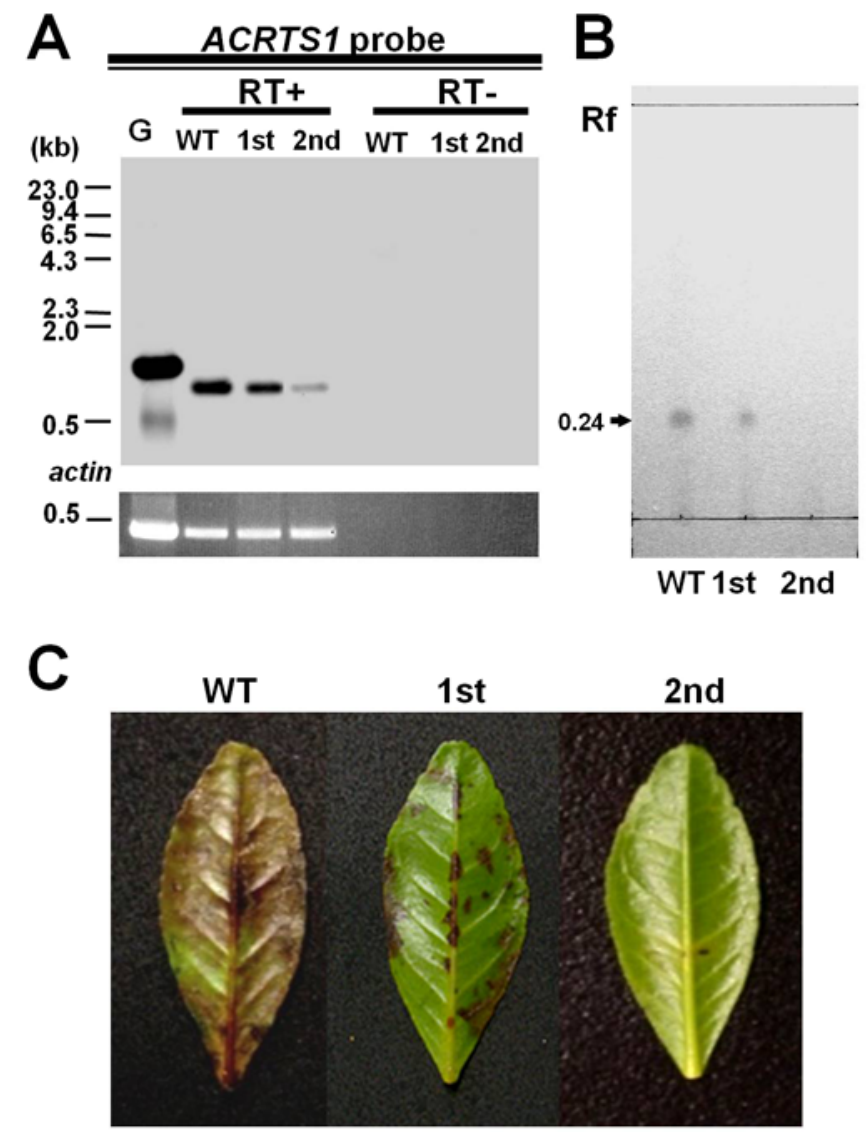

Fig. 4. Detection of ACRTS1 transcripts, ACR-toxin production, and pathogenicity of ACRTS1 disruptants of Alternaria alternata rough lemon pathotype. A, Reverse transcription-polymerase chain reaction (RT-PCR) detection of ACRTS1 transcripts in wild-type HC1 (lane WT), single-copy ACRTS1 disruptant D16 (1st) and double-copy disruptant Rep28 (2nd), respectively. RT-PCR products were hybridized with ACRTS1 probe following agarose gel fractionation and transfer to membrane. RT+ and RT- indicates PCR with and without addition of reverse transcriptase, respectively. Amplification of the actin gene was used as a positive control for RT-PCR and to indicate the use of an equal amount of RNA as the template as described previously (1,32-34). Sizes of DNA marker fragments (HindIII-digested $\lambda \mathrm{DNA}$ ) are indicated at left. B, TLC analysis for ACR-toxin in extracts from culture filtrates of wild-type HC1 (WT), single-copy ACRTS1 disruptant D16 (1st) and double-copy disruptant Rep28 (2nd). C, Disease symptoms following inoculation of rough lemon leaves with conidia from wild-type $\mathrm{HC} 1$ (WT), single-copy ACRTS1 disruptant D16 (1st) and double-copy disruptant Rep28 (2nd).

\section{DISCUSSION}

A. alternata is a cosmopolitan saprophytic fungus that is readily recovered from many different habitats $(43,49)$. In contrast, a small number of A. alternata isolates produce hostspecific toxins (HST) and are pathogenic to a limited number of species or cultivars of plants $(24,25,39)$. HST-producing strains of A. alternata have been categorized into seven distinct pathotypes including rough lemon, tangerine, Japanese pear, strawberry, apple, tomato, and tobacco based on their selective pathogenicity and highly restricted host ranges $(24,25,39)$. The pathogenicity of each pathotype depends entirely on the production of a specific HST that is selectively toxic to the host of each pathotype $(24,25,39)$. Therefore, study of the genetic basis of HST production is a necessary step in understanding the mechanism of pathogenicity of A. alternata. The genes responsible for HST production in the tangerine, Japanese pear, strawberry, tomato, and apple pathotypes of $A$. alternata and their genomic organi-

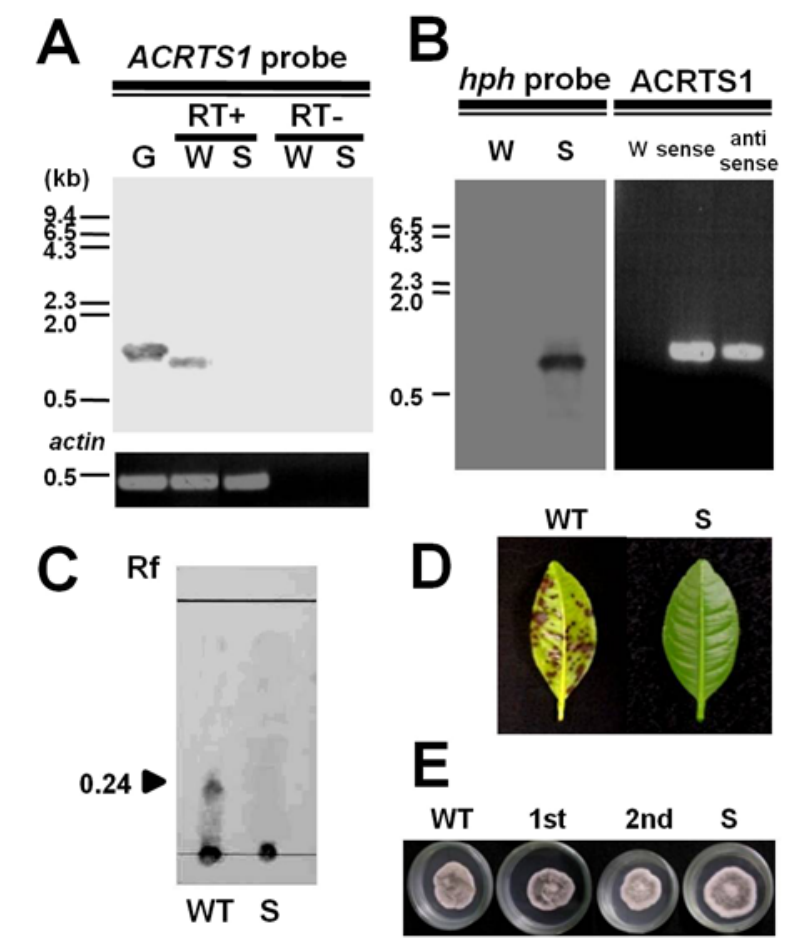

Fig. 5. Effects of RNA silencing of ACRTS1 on ACRTS1 transcript abundance, ACR-toxin production, and pathogenicity in Alternaria alternata rough lemon pathotype. A, Reverse transcription-polymerase chain reaction (RT-PCR) detection of ACRTS1 transcripts in wild-type HC1 (lane WT) and RNAsilenced mutant S14 (S). RT-PCR products were hybridized with ACRTS1 probe following agarose gel fractionation and transfer to membrane. RT+ and RT- indicates PCR with and without addition of reverse transcriptase, respectively. Amplification of the actin gene was used as positive control for RT-PCR and to indicate use of an equal amount of RNA as the template as described previously $(1,32-34)$. (G) indicates use of genomic DNA as the template for PCR amplification. B, Insertion analysis of pASY-ACRTS1 by genomic PCR following Southern blot of $h p h$ in wild-type $\mathrm{HCl}(\mathrm{W})$ and ACRTS1-silenced mutant S14 (S). Insertion of the vector was confirmed by genomic PCR of wild-type HC1 (W) and ACRTS1-silenced mutant S14 (S) using primer sets of hphF1/hphR1, PacCITF1multisite/ACRTS1R3HindIII (sense) and PacCITR1multisite/ACRTS1R3PstI (antisense). PCR product by hphF1/hphR1 primers was hybridized with hph probe $(1,32,33)$ after agarose gel fractionation. PCR products of PacCITF1multisite/ACRTS1R3HindIII primers and PacCITR1multisite/ACRTS1R3PstI primers were sequenced for confirmation. C, TLC analysis for ACR-toxin in extracts from culture filtrates of wild-type HC1 (lane WT) and RNA-silenced mutant S14 (S). D, Disease symptoms following inoculation of rough lemon leaves with conidia from wild type HC1 (lane WT) and RNA-silenced mutant (S) on rough lemon leaves. E, Morphology and growth on PDA plate of wild type (WT), singlecopy disruptant D16 (1st), double-copy disruptant Rep28 (2nd), and RNAsilenced mutant $(\mathrm{S})$, respectively. 
zation have been identified $(1,3,4,14-20,29,30,32-34,44,47,48)$. In this study, we have for the first time identified an ACR-toxin biosynthesis gene, designated ACRTS1, located in the small 1.5$\mathrm{Mb}$ chromosome from the rough lemon pathotype of A. alternata. Mass sequencing data of the $1.5-\mathrm{Mb}$ chromosome showed three putative ORFs, present only in the genome from the rough lemon pathotype of $A$. alternata, including ACRTS1 that encodes a putative hydroxylase (this study), ACRTS2 that encodes a putative polyketide synthase (data not shown), and ACRTS3 that encodes a putative transcriptional regulator (data not shown).

Since multiple copies of ACRTS1 were expected to be present in the 1.5-Mb chromosome by Southern blot analysis of genomic DNA digested with various restriction enzymes, a combination of targeting/gene replacement mediated by homologous recombination and RNA silencing was used to examine the function of these genes in ACR-toxin biosynthesis. Disruption of two copies of ACRTS1 by targeting/gene replacement mediated by homologous recombination significantly reduced the production of ACR-toxin as well as the pathogenicity of the toxin producer; however, ACRTS1 transcripts were still detected in the disruptants. Thus RNA silencing was introduced for further examination of the function of ACRTS1 in the biosynthesis of ACR-toxin. Transformation constructs creating a hairpin structure in RNA using sense and antisense sequences of the target gene with an intron sequence-based hairpin head spacer are known as an effective and relatively stable means of RNA silencing in $A$. alternata (1,33). We previously demonstrated the efficiency of RNA silencing in A. alternata using the green fluorescence protein (GFP) gene as a monitoring marker and ACT-toxin biosynthesis genes ACTT2 or ACTTS2 in the tangerine pathotype of A. alternata $(1,33)$. For ACRTS1, the frequency of RNAsilenced transformants with reduced ACR-toxin production was similar or greater (98\%) compared with other reports of RNAsilencing in filamentous fungi $(8,10,13,21,28,31,35,36,38)$. However, the frequency ( $2 \%$ ) of silenced transformants with no detectable ACRTS1 transcript, ACR-toxin production or pathogenicity was low, and this low efficiency might be related to the copy number of the target genes. The frequency of completely silenced transformants for other HST biosynthesis genes with lower copy number in the rough lemon or tangerine pathotype of A. alternata was generally higher than the frequency recovered for silencing of ACRTS1 (data not shown). We concluded that there are three or more copies of ACRTS1 in the genome because a knock-out of two copies by gene disruption and gene replacement did not completely abolish the toxin production. Although ACRTS1 could not be conventionally disrupted due to multiple paralogs in the genome, the high sequence identity among ACRTS1 paralogs was likely an advantage for the use of RNA silencing, which allows the knock down of target transcripts from all paralogs simultaneously $(1,33)$. Since the target recognition process is highly sequence specific but does not always require $100 \%$ identity (9), sequence identity among functional copies of ACRTS1 is likely high enough to be recognized by the ACRTS1siRNA-oriented RNA-induced silencing complex (RISC). We obtained three ACRTS1 RNA-silenced transformants, which knocked down ACRTS1 transcripts to undetectable levels in Southern blots after RT-PCR. The transformants also did not produce ACR-toxin and lost pathogenicity to rough lemon. These results indicated that ACRTS1 is the essential gene in ACR-toxin biosynthesis in the rough lemon pathotype of A. alternata and is required for full virulence of this fungus.

The chemical structure of the major form of ACR-toxin (ACRtoxin I) is a C19 polyalcohol with a $\alpha$-dihydropyrone ring $(12,37)$. The long chain fatty acid component of ACR-toxin has structural features typical of polyketides. One ORF (ACRTS2), predicted to encode a polyketide synthase (PKS), was identified by mass sequencing of $\mathrm{BAC}$ clone $3 \mathrm{M} 8$ from the rough lemon pathotype of A. alternata and is only present in the genome of
ACR-toxin producers (data not shown). Preliminary data showing the RNA silencing of ACRTS2 has demonstrated that this gene is also essential for ACR-toxin biosynthesis (Y. Izumi, Y. Miyamoto, E. Kamei, K. Ohtani, T. Fukumoto, K. Gomi, and K. Akimitsu, unpublished data) and supporting the hypothesis that ACR-toxins are polyketide secondary metabolites. Although ACRTS1, encoding a hydroxylase, is essential for the biosynthesis of ACR-toxin, the exact role of this enzyme in the biosynthetic pathway of ACRtoxin is not yet clear. Based on the hypothesized ACR-toxin biosynthetic pathway (Supplemental Figure 3), the hydroxylase encoded by ACRTS1 is likely used for closing the ring structure at the end of the polyketide chain to complete the synthesis of ACRtoxin according to the predicted synthetic pathway of PKS.

\section{ACKNOWLEDGMENTS}

We thank L. W. Timmer for providing strains of A. alternata from Florida; M. Kodama and H. Otani, Tottori University, for valuable discussions and providing strain O-94; and T. Tsuge, Nagoya University, for valuable discussions and providing strains of G31, G90-A2, NAF-3, NAF-8, 91080804, AL-4, AM-1, O-159, No. 122-2, and AT-204. This work was supported by grants for scientific research on priority area (S) from Ministry of Education, Culture, Sports, Science, and Technology of Japan; Precursory Research for Embryonic Science and Technology from Japan Science and Technology Agency.

\section{LITERATURE CITED}

1. Ajiro, N., Miyamoto, Y., Masunaka, A., Tsuge, T., Yamamoto, M., Ohtani, K., Fukumoto, T., Gomi, K., Peever, T. L., Izumi, Y., Tada, Y., and Akimitsu, K. 2010. Role of the host-selective ACT-toxin synthesis gene ACTTS2 encoding an enoyl-reductase in pathogenicity of the tangerine pathotype of Alternaria alternata. Phytopathology 100:120-126.

2. Akagi, Y., Akamatsu, H., Otani, H., and Kodama, M. 2009. Horizontal chromosome transfer: A mechanism for the evolution and differentiation of a plant pathogenic fungus. Eukaryot. Cell 8:1732-1738.

3. Akamatsu, H., Itoh, Y., Kodama, M., Otani, H., and Kohmoto, K. 1997. AAL-toxin-deficient mutants of Alternaria alternata tomato pathotype by restriction enzyme-mediated integration. Phytopathology 87:967-972.

4. Akamatsu, H., Otani, H., and Kodama, M. 2003. Characterization of a gene cluster for host-specific AAL-toxin biosynthesis in the tomato pathotype of Alternaria alternata. Fungal Genet. Newsl. 50:355.

5. Akamatsu, H., Taga, M., Kodama, M., Johnson, R., Otani, H., and Kohmoto, K. 1999. Molecular karyotypes for Alternaria plant pathogens known to produce host-specific toxins. Curr. Genet. 35:647-656.

6. Akimitsu, K., Kohmoto, K., Otani, H., and Nishimura, S. 1989. Hostspecific effect of toxin from the rough lemon pathotype of Alternaria alternata on mitochondria. Plant Physiol. 89:952-931.

7. Akimitsu, K., Peever, T. L., and Timmer, L. W. 2003. Molecular, ecological and evolutionary approaches to understanding Alternaria diseases of citrus. Mol. Plant Pathol. 4:435-446.

8. Cogoni, C., Irelan, J., Schumacher, M., Schmidhauser, T. J., Selker, E. U., and Macino, G. 1996. Transgene silencing of the al-1 gene in vegetative cells of Neurospora is mediated by a cytoplasmic effector and does not depend on DNA-DNA interactions or DNA methylation. EMBO J. 15:3153-3163

9. Elbashir, S. M., Lendeckel, W., and Tuscchl, T. 2001. RNA interference is mediated by 21- and 22-nucleotide RNAs. Genes Dev. 15:188-200.

10. Fitzgerald, A., van Kan, J. A. L., and Plummer, K. M. 2004. Simultaneous silencing of multiple genes in the apple scab fungus, Venturia inaequalis, by expression of RNA with chimeric inverted repeats. Fungal Genet. Biol. 41:963-971.

11. Gardner, J. M., Kono, Y., Tatum, J. H., Suzuki, Y., and Takeuchi, S. 1985. Plant pathotoxins from Alternaria citri: The major toxin specific for rough lemon plants. Phytochemistry 24:2861-2867.

12. Gardner, J. M., Kono, Y., Tatum, J. H., Suzuki, Y., and Takeuchi, S. 1985. Structure of the major component of ACRL-toxins, host-specific pathotoxic compound produced by Alternaria citri. Agric. Biol. Chem. 49:1235-1238.

13. Hammond, T. M., and Keller, N. P. 2005. RNA silencing in Aspergillus nidulans is independent of RNA-dependent RNA polymerases. Genetics 169:607-617.

14. Harimoto, T., Hatta, R., Kodama, M., Yamamoto, M., Otani, H., and Tsuge, T. 2007. Expression profiles of genes encoded by the supernumerary chromosome controlling AM-toxin biosynthesis and pathogenicity in the apple pathotype of Alternaria alternata. Mol. Plant- 
Microbe Interact. 12:1463-1476.

15. Harimoto, T., Tanaka, T., Kodama, M., Yamamoto, M., Otani, H., and Tsuge, T. 2008. Multiple copies of AMT2 are prerequisite for the apple pathotype of Alternaria alternata to produce enough AM-toxin for expressing pathogenicity. J. Gen. Plant Pathol. 74:222-229.

16. Hatta, R., Ito, K., Hosaki, Y., Tanaka, T., Tanaka, A., Yamamoto, M., Akimitsu, K., and Tsuge, K. 2002. A conditionally dispensable chromosome controls host-specific pathogenicity in the fungal plant pathogen Alternaria alternata. Genetics 161:59-70.

17. Isshiki, A., Akimitsu, K., Yamamoto, M., and Yamamoto, H. 2001. Endopolygalacturonase is essential for citrus black rot caused by Alternaria citri but not brown spot caused by Alternaria alternata. Mol. PlantMicrobe Interact. 14:749-757.

18. Ito, K., Tanaka, A., Hatta, R., Yamamoto, M., Akimitsu, K., and Tsuge, T. 2004. Dissection of the host range of the fungal plant pathogen Alternaria alternata by modification of secondary metabolism. Mol. Microbiol. 52:399-411.

19. Johnson, L. J., Johnson, R. D., Akamatsu, H., Salamiah, A., Otani, H., Kohmoto, K., and Kodama, M. 2001. Spontaneous loss of a conditionally dispensable chromosome from the Alternaria alternata apple pathotype leads to loss of toxin production and pathogenicity. Curr. Genet. 40:65-72.

20. Johnson, R. D., Johnson, L., Itoh, Y., Kodama, M., Otani, H., and Kohmoto, K. 2000. Cloning and characterization of a cyclic peptide synthetase gene from Alternaria alternata apple pathotype whose product is involved in AM-toxin synthesis and pathogenicity. Mol. Plant-Microbe Interact. 13:742-753.

21. Kadotani, N., Nakayashiki, H., Tosa, Y., and Mayama, S. 2003. RNA silencing in the phytopathogenic fungus Magnaporthe oryzae. Mol. PlantMicrobe Interact. 16:769-776.

22. Kohmoto, K., Akimitsu, K., and Otani, H. 1991. Correlation of resistance and susceptibility of citrus to Alternaria alternata with sensitivity to hostspecific toxins. Phytopathology 81:719-722.

23. Kohmoto, K., Kondoh, Y., Kohguchi, T., Otani, H., Nishimura, S., and Sheffer, R. P. 1984. Ultrastructural changes in host leaf cells caused by host-selective toxin of Alternaria alternata from rough lemon. Can. J. Bot. 62:2485-2492.

24. Kohmoto, K., and Otani, H. 1991. Host recognition by toxigenic plant pathogens. Experientia 47:755-764.

25. Kohmoto, K., Otani, H., and Tsuge, T., (1995) Alternaria alternata pathogens. Pages 51-63 in: Pathogenesis and Host-Specificity in Plant Diseases: Histopathological, Biochemical Genetic and Molecule Bases, Vol. II, Eukaryotes. K. Kohmoto, U. S. Singh, and R. P. Singh, eds. Pergamon, Oxford.

26. Kohmoto, K., Sheffer, R. P., and Whiteside, J. O. 1979. Host-selective toxins from Alternaria citri. Phytopathology 69:667-671.

27. Kusaba, M., and Tsuge, T. 1995. Phylogeny of Alternaria fungi known to produce host-specific toxins on the basis of variation in internal transcribed spacers of ribosomal DNA. Curr. Genet. 28:491-498.

28. Liu, H., Cottrell, T. R., Pierini, L. M., Goldman, W. E., and Doering T. L. 2002. RNA interference in the pathogenic fungus Cryptococcus neoformans. Genetics 160:463-470.

29. Masunaka, A., Ohtani, K., Peever, T. L., Timmer, L. W., Tsuge, T., Yamamoto, M., Yamamoto, H., and Akimitsu, K. 2005. An isolate that is pathogenic to both tangerines and rough lemon and produces two hostselective toxins, ACT- and ACR-toxins. Phytopathology 95:241-247.

30. Masunaka, A., Tanaka, A., Tsuge, T., Peever, T. L., Timmer, L. W., Yamamoto, M., Yamamoto, H., and Akimitsu, K. 2000. Distribution and characterization of $A K T$ homologs in the tangerine pathotype of Alternaria alternata. Phytopathology 90:762-768.

31. McDonald, T., Brown, D., Keller, N. P., and Hammond, T. M. 2005. RNA silencing of mycotoxin production in Aspergillus and Fusarium species. Mol. Plant-Microbe Interact. 18:539-545.

32. Miyamoto, Y., Ishii, Y., Honda, A., Masunaka, A., Tsuge, T., Yamamoto, M., Ohtani, K., Fukumoto, T., Gomi, K., Peever, T. L., and Akimitsu, K. 2009. Function of genes encoding acyl-CoA synthetase and enoyl-CoA hydratase for host-selective ACT-toxin biosynthesis in the tangerine pathotype of Alternaria alternata. Phytopathology 99:369-377.

33. Miyamoto, Y., Masunaka, A., Tsuge, T., Yamamoto, M., Ohtani, K., Fukumoto, T., Gomi, K., Peever, T. L., and Akimitsu, K. 2008. Functional analysis of a multicopy host-selective ACT-toxin biosynthesis gene in the tangerine pathotype of Alternaria alternata using RNA silencing. Mol. Plant-Microbe Interact. 21:1591-1599.

34. Miyamoto, Y., Masunaka, A., Tsuge, T., Yamamoto, M., Ohtani, K., Fukumoto, T., Gomi, K., Peever, T. L., Tada, Y., Ichimura, K., and Akimitsu, K. 2010. ACTTS3 encoding a polyketide synthase is essential for the biosynthesis of ACT-toxin and pathogenicity in the tangerine pathotype of Alternaria alternata. Mol. Plant-Microbe Interact. 23:406414.

35. Moriwaki, A., Ueno, M., Arase, S., and Kihara, J. 2007. RNA-mediated gene silencing in the phytopathogenic fungus Bipolaris oryzae. FEMS Microbiol. Lett. 269:85-89.

36. Mouyna, I., Henry, C., Doering, T. L., and Latge, J. P. 2004. Gene silencing with RNA interference in the human pathogenic fungus Aspergillus fumigates. FEMS Microbiol. Lett. 237:317-324.

37. Nakatsuka, S., Goto, T., Kohmoto, K., and Nishimura, S. 1986. Hostspecific phytotoxins. Pages 11-18 in: Natural Products and Biological Activities. H. Imura, T. Goto, T. Murachi, and T. Nakajima, eds. University of Tokyo Press, Tokyo.

38. Nakayashiki, H., Hanada, S., Quoc, N. B., Kadotani, N., Tosa, Y., and Mayama, S. 2005. RNA silencing as a tool for exploring gene function in ascomycete fungi. Fungal Genet. Biol. 42:275-283.

39. Nishimura, S., and Kohmoto, K. 1983. Host-specific toxins and chemical structures from Alternaria species. Annu. Rev. Phytopathol. 21:87-116.

40. Ohtani, K., Yamamoto, H., and Akimitsu, K. 2002. Sensitivity to Alternaria alternata toxin in citrus because of altered mitochondrial RNA processing. Proc. Natl. Acad. Sci. USA 99:2439-2444.

41. Peever, T. L., Canihos, Y., Olsen, L., Ibanez, A., Liu, Y. C., and Timmer, L. W. 1999. Population genetic structure and host specificity of Alternaria spp. causing brown spot of Minneola tangelo and rough lemon in Florida. Phytopathology 89:851-860.

42. Peever, T. L., Su, G., Carpenter-Boggs, L., and Timmer, L. W. 2004. Molecular systematics of citrus-associated Alternaria species. Mycologia 96:119-134.

43. Rotem, J. 1994. The genus Alternaria. Pages 1-10 in: Biology, Epidemiology, and Pathogenicity. The American Phytopathological Society, St. Paul, MN.

44. Ruswandi, S., Kitani, K., Akimitsu, K., Tsuge, T., Shiraishi, T., and Yamamoto, M. 2005. Structural analysis of cosmid clone pcAFT-2 carrying AFT10-1 encoding an acyl-CoA dehydrogenase involved in AFtoxin production in the strawberry pathotype of Alternaria alternata. J. Gen. Plant Pathol. 71:107-116.

45. Sanger, F., Nicklen, S., and Coulson, A. R. 1977. DNA sequencing with chain-terminating inhibitors. Proc. Natl. Acad. Sci. USA 74:5463-5467.

46. Scheffer, R. P., and Livingston, R. S. 1984. Host-selective toxins and their role in plant diseases. Science 223:17-21.

47. Tanaka, A., Shiotani, H., Yamamoto, M., and Tsuge, T. 1999. Insertional mutagenesis and cloning of the genes required for biosynthesis of the host-specific AK-toxin in the Japanese pear pathotype of Alternaria alternata. Mol. Plant-Microbe Interact. 12:691-702.

48. Tanaka, A., and Tsuge, T. 2000. Structural and functional complexity of the genomic region controlling AK-toxin biosynthesis and pathogenicity in the Japanese pear pathotype of Alternaria alternata. Mol. PlantMicrobe Interact. 13:975-986.

49. Thomma, B. P. H. J. 2003. Alternaria spp.: From general saprophyte to specific parasite. Mol. Plant-Microbe Interact. 4:225-236.

50. Walton, J. D. 1996. Host-selective toxins: Agents of compatibility. Plant Cell 8:1723-1733.

51. Wolpert, T. J., Dunkle, L. D., and Ciuffetti, L. M. 2002. Host-selective toxins and avirulence determinants: What's in a name? Annu. Rev. Phytopathol. 40:251-285.

52. Yoder, O. C. 1980. Toxins in pathogenesis. Annu. Rev. Phytopathol. 18:103-129. 